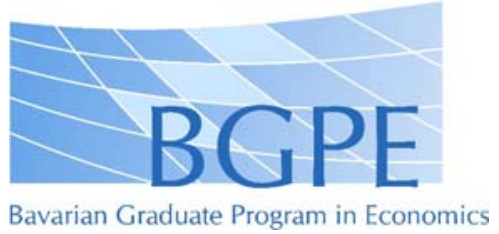

BGPE Discussion Paper

No. 6

\title{
Gender Differences in Labor Supply to Monopsonistic Firms: An Empirical Analysis Using Linked Employer-Employee Data from Germany
}

\section{Boris Hirsch, Thorsten Schank, Claus Schnabel}

November 2006

ISSN 1863-5733

Editor: Prof. Regina T. Riphahn, Ph.D.

Friedrich-Alexander-University Erlangen-Nuremberg

(c) Boris Hirsch, Thorsten Schank, Claus Schnabel 


\title{
Gender Differences in Labor Supply to Monopsonistic Firms: An Empirical Analysis Using Linked Employer-Employee Data from Germany
}

\author{
Boris Hirsch ${ }^{a}$, Thorsten Schank ${ }^{b}$, Claus Schnabe $]^{c}$
}

Abstract: This paper investigates women's and men's labor supply to the firm within a structural approach based on a dynamic model of new monopsony. Using methods of survival analysis and a linked employer-employee dataset for Germany, we find that labor supply elasticities are small (0.9-2.4) and that women's labor supply to the firm is substantially less elastic than men's (which is the reverse of gender differences in labor supply usually found at the level of the market). One implication of these findings is that the gender pay gap could be the result of wage discrimination by profit-maximizing monopsonistic employers.

Zusammenfassung: Mithilfe eines strukturellen Ansatzes, der auf einem dynamischen Monopsonmodell beruht, untersuchen wir das Arbeitsangebot von Frauen und Männern auf Firmenebene. Die unter Verwendung von Verweildauermodellen und eines deutschen kombinierten Firmen-Beschäftigten-Datensatzes geschätzten Arbeitsangebotselastizitäten sind gering $(0,9-2,4)$ und fallen für Frauen erheblich geringer aus als für Männer (während man für das Arbeitangebot auf Marktebene üblicherweise eine höhere Elastizität für Frauen findet). Eine Implikation hieraus ist, dass geschlechtsspezifische Lohndifferentiale die Folge von Lohndiskriminierung seitens gewinnmaximierender monopsonistischer Arbeitgeber sein könnten.

Keywords: labor supply, monopsony, gender, discrimination

New JEL-Classification: J42, J60, J71

a Boris Hirsch, Friedrich-Alexander-Universität Erlangen-Nürnberg, Lehrstuhl für Arbeitsmarkt- und Regionalpolitik, Lange Gasse 20, D-90403 Nürnberg, boris.hirsch@wiso.unierlangen.de.

$b \quad$ Thorsten Schank, Friedrich-Alexander-Universität Erlangen-Nürnberg, Lehrstuhl für Arbeitsmarkt- und Regionalpolitik, Lange Gasse 20, D-90403 Nürnberg, thorsten.schank@wiso.unierlangen.de.

c Claus Schnabel, Friedrich-Alexander-Universität Erlangen-Nürnberg, Lehrstuhl für Arbeitsmarkt- und Regionalpolitik, Lange Gasse 20, D-90403 Nürnberg, claus.schnabel@wiso.unierlangen.de. 
Empirical studies usually find that women's labor supply is more elastic than men's at the level of the market, but some researchers argue informally that this relationship reverses at the level of the individual firm.

(Boal \& Ransom 1997, p. 99)

\section{Introduction}

Conventional wisdom tells us that women's market labor supply is more elastic than men's. This insight results from a vast number of empirical studies which investigate whether and how much labor individuals supply by using data from individual- or household-level surveys. Theoretical labor supply models also take the perspective of employees. This means that employers' perspective, i.e. the demand-side of labor, usually plays only a minor role.

From the perspective of a single firm, however, it does not matter whether an individual supplies labor generally, but whether he or she supplies it to this firm or not. Furthermore, not only unemployed but also employed workers are potential suppliers of labor to this firm. Therefore firm-level labor supply differs substantially from market-level labor supply. Although women's labor supply is more elastic than men's at the market-level, it might be less elastic than men's at the firm-level, giving rise to steeper labor supply curves for women to the firm. Reasons for this could be different preferences over non-wage job characteristics and a higher degree of immobility. For instance, women's job moves might be less motivated by pecuniary considerations, but to a larger extent by the job's location (e.g., near nursery school) or the working hours offered (e.g., the possibility of working part-time).

Bearing this in mind, profit-maximizing firms may take advantage of genderspecific differences in supply elasticities by exercising wage discrimination, i.e. by paying different wages to women and men, ceteris paribus. This, in turn, could be one reason of the gender pay gap which is another stylized fact of labor markets. Theoretical considerations on this sort of wage discrimination originate from Robinson (1933), who was the first to apply Pigou's (1932) concept of third-degree price discrimination at a commodity market to the labor market. Hence, Robinsonian discrimination differs fundamentally from Becker's (1971) concept of discrimination due to distaste because firms' actions when engaging in wage discrimination remain profit-maximizing as their considerations are not biased by irrational prejudices.

Since Robinson's (1933) analysis assumes monopsony power in the classic sense of a single employer one might doubt its relevance. The new monopsony literature, however, whose first systematic exposition and application to nearly all traditional topics of labor economics is given by Manning (2003), emphasizes that monopsony 
power may even arise if there are many firms competing for workers. Models of new monopsony yield upward-sloping firm-level labor supply curves (even without concentration on the demand-side) due to search frictions, heterogenous preferences among workers and mobility costs. Thus, Robinsonian discrimination might be a widespread phenomenon in actual labor markets.

Whether firm-level labor supply differs between men and women has been investigated in no more than two studies (according to our knowledge). Barth \& Dale-Olsen (1999) find that firms' turnover rates are less elastic for women than for men, but they do not report elasticities. Ransom \& Oaxaca (2005) find for a chain of grocery stores that female labor supply to the firm is less elastic than male labor supply with elasticities of 2.7 and 3.5, respectively. Both studies rely on Burdett \& Mortensen's (1998) equilibrium search model with wage posting, where transitions to and from non-employment are totally wage-inelastic and workers change firms whenever they are offered wages above their current wage.

In contrast, we utilize a structural approach resting on methods of survival analysis proposed by Manning (2003) which avoids these restrictive assumptions by introducing wage-elastic transitions from and to non-employment as well as stochastic transitions among employers. Other than Manning (2003) who uses datasets based on individual- or household-level surveys, we use a large German linked employeremployee dataset, the LIAB, to take the demand-side into consideration, too. Moreover, by choosing Cox proportional hazard models to model transitions (instead of exponential hazard models) we avoid specifying duration dependence so that our approach gains additional flexibility.

The paper is organized as follows: Section 2 briefly develops a highly stylized version of Burdett \& Mortensen's (1998) model similar to Manning's (2003) exposition. This is enriched in section 3, where our empirical specification is derived. Section 4 describes the dataset used, while section 5 presents and discusses our empirical results. Section 6 draws some conclusions.

\section{Theory}

In this section we present the structural approach we are going to use when estimating men's and women's labor supply to the firm. The starting point is a simple model of dynamic monopsony, where we consider a profit-maximizing, non-discriminating monopsonist in discrete time. In the spirit of new monopsony theory, we regard the firm as a monopsonist in the sense that it faces an upward-sloping labor supply 
curve due to search frictions, heterogenous preferences of workers or mobility costs 1 With this we follow Manning (2003, p. 10) in arguing 'that labor economics should adopt a similar attitude to that in industrial organization and start analysis from the position that all employers have some labor market power'.

Workers are assumed to leave the firm in consideration in period $t$ at a separation rate $s\left(w_{t}\right) \in(0,1)$ which depends negatively on the wage paid by the firm $w_{t}$, i.e. $s^{\prime}<0$. Total separations in period $t$ are therefore $s\left(w_{t}\right) L_{t-1}$, where $L_{t-1}$ denotes the firm's employment in period $t-1$. On the other hand, the flow of recruits $R\left(w_{t}\right)$ arriving at the firm depends positively on the wage paid, i.e. $R^{\prime}>0$. Hence, the labor supply to the firm in period $t$ depends on $w_{t}$ and $L_{t-1}$ and is given by

$$
L_{t}\left(w_{t}, L_{t-1}\right)=\left[1-s\left(w_{t}\right)\right] L_{t-1}\left(w_{t-1}, L_{t-2}\right)+R\left(w_{t}\right)
$$

Given a steady state with $L_{t}\left(w_{t}, L_{t-1}\right) \equiv L(w)$ and $w_{t} \equiv w$, firm's hires $R(w)$ and separations $s(w) L(w)$ must be balanced which gives a steady-state workforce of

$$
L(w)=R(w) / s(w)
$$

with $L^{\prime}>0$ so that steady-state employment depends positively on the firm's wage. Taking logarithms and differentiation of (2) gives

$$
\varepsilon_{L w}^{L}=\varepsilon_{R w}-\varepsilon_{s w}
$$

where $\varepsilon_{L w}^{L} \equiv L^{\prime}(w) w / L(w)$ denotes the long-run wage elasticity of firm's labor supply, $\varepsilon_{R w} \equiv R^{\prime}(w) w / R(w)$ the wage elasticity of the flow of recruits and $\varepsilon_{s w} \equiv$ $s^{\prime}(w) w / s(w)$ the wage elasticity of the separation rate.

The simple dynamic monopsony framework can be developed further by making use of the Burdett \& Mortensen (1998) model of equilibrium search theory with wage posting. In order to keep the analysis simple, we closely follow the presentation by Manning (2003). Suppose there are $m$ homogenous workers and $n$ homogenous firms, where we make use of the technical assumption that there exist formally continua of both. Workers are either employed or unemployed, searching for jobs both on-thejob and off-the-job. They receive job offers at an exogenous job offer arrival rate $\lambda_{e}$ when employed and $\lambda_{u}$ when unemployed. Job offers are drawn at random from the wage distribution across employers $F(w)$ with density $f(w)$, where each employer pays a single wage to all his employees and sets this wage once-for-all to maximize

$1 \quad$ Surveys of monopsony in the labor market are provided by Boal \& Ransom (1997) and Bhaskar et al. (2002). 
his steady-state profits (which implies zero time preference of employers). Existing jobs break off at a job destruction rate $\delta$ which is assumed as exogenous. Let $b$ denote workers' opportunity cost of employment, i.e. the utility flow per instant when unemployed. Workers' reservation wage $w^{R}$ depends on whether on-the-job or off-the-job search is more prospective. If neither on-the-job nor off-the-job search is more prospective $b$ also gives workers' reservation wage, otherwise we have $w^{R} \lessgtr b$ if and only if $\lambda_{e} \gtrless \lambda_{u}$ (cf. Burdett \& Mortensen 1998). Furthermore we assume that workers' marginal and average revenue product of labor is constant at $p$ per instant.

Employed workers accept job offers, whenever they are offered wages above their current wage, while unemployed workers accept every offer..$^{2}$ In equilibrium, all firms must gain the same level of profits $\pi$ which is given by $\pi=(p-w) L\left(w \mid w^{R}, F\right)$, where $L\left(w \mid w^{R}, F\right)$ is the labor supply of a firm offering wage $w$ given some wage distribution $F$ and workers' reservation wage $w^{R}$, which are explained endogenously. Now consider the firm's separation rate $s(w)$. As existing matches break off at rate $\delta$ and employed workers receive job offers at rate $\lambda_{e}$, which they will accept if they pay more than their current wage, $s(w)$ is given by

$$
s(w)=\delta+\lambda_{e}[1-F(w)]
$$

The number of recruits $R(w)$ for a firm paying wage $w$ is represented by

$$
R(w)=\lambda_{u} u+\lambda_{e} \int_{w^{R}}^{w} L(x \mid \cdot) f(x) d x
$$

where $u$ denotes the steady-state number of unemployed workers. (5) holds because unemployed workers receive acceptable job offers at rate $\lambda_{u}$, whereas only employed workers earning less than $w$ are willing to accept the firm's offer.

Differentiation of both (4) and (5) and some rearrangement yield

$$
\varepsilon_{R w}=-\varepsilon_{s w} \Longleftrightarrow \varepsilon_{L w}^{L}=-2 \varepsilon_{s w}
$$

because we are in a steady state so that (3) applies. Therefore absolute values of recruitment and separation rate elasticities are the same. Roughly speaking, this holds since one firm's wage-related separation is another firm's wage-related hiring and since hiring from unemployment as well as separations to unemployment are totally wage-inelastic. Making use of this result, we are able to estimate the long-

$2 \quad$ This holds as $w^{R}$ is the lower bound of the wage distribution across employers $F$ because all firms offering a wage $w$ beyond $w^{R}$ would be unable to recruit any workers at all and would thus make no profits. 
run labor supply elasticity by simply estimating the separation rate elasticity. This can be done by using existing estimation procedures, such as hazard rate models (e.g., Campbell 1993), whereas we do not have such procedures for obtaining the recruitment elasticity.

This specification, however, is rather restrictive since it is assumed that workers change their jobs if and only if they are offered wages above their current wage and that transitions from and to unemployment are wage-inelastic. In the first step, therefore some stochastic component is introduced by allowing for stochastic transitions among employers. Let $\varphi(x / w)$ denote the probability that a worker currently paid wage $w$ quits and accepts a job offering wage $x$. Since $\varphi$ is a probability $\varphi \in[0,1]$ holds. Furthermore assume that $\varphi$ is continuously differentiable with $\varphi^{\prime} \geq 0$, i.e. the probability that a worker changes his job monotonously increases in the ratio of the offered and the currently paid wage $!^{3}$ Let $\bar{w}$ denote the highest wage paid, that is the maximum of F's support, and let $\underline{w}$ denote the lowest wage paid, that is the minimum of F's support. Using $\varphi$ as defined above the separation rate of a firm paying wage $w$ is given by

$$
s(w)=\delta+\lambda_{e} \int_{\underline{w}}^{\bar{w}} \varphi(x / w) f(x) d x .
$$

Hence, some workers with current wage $w$ might even accept a job offering a wage $x<w$. Similarly, the number of recruits for a firm paying $w$ is represented by

$$
R(w)=\lambda_{u} u+\lambda_{e} \int_{\underline{w}}^{\bar{w}} \varphi(w / x) L(x \mid \cdot) f(x) d x .
$$

Equations (7) and (8) can now be used to get

$$
\int_{\underline{w}}^{\bar{w}} \varepsilon_{s w}(x) R(x) f(x) d x=-\int_{\underline{w}}^{\bar{w}} \varepsilon_{R w}(x) R(x) f(x) d x,
$$

where $\varepsilon_{s w}(w)$ and $\varepsilon_{R w}(w)$ indicate that elasticities do not have to be constant for different wages. $4^{4}(9)$ says that absolute values of recruit-weighted recruitment and separation rate elasticities are the same. In particular this means that for constant elasticities absolute values of both are the same so that (6) will hold again.

While introducing a stochastic component made the transition behavior from employment at one firm to employment at another firm more realistic, transitions

$3 \quad$ Obviously, the model considered so far is nested as a limit case with $\varphi(x / w)=0$ if $x \leq w$ and $\varphi(x / w)=1$ if $x>w$.

4 A formal proof of this is given by Manning (2003, p. 109). 
from and to unemployment are still totally wage-inelastic.5 Let $s^{e}(w)$ denote the separation rate to employment, $s^{u}(w)$ the separation rate to unemployment and $\theta_{s}(w)$ the share of separations to employment which is assumed to vary with the wage paid. Then the total separation rate is given by

$$
s(w)=s^{e}(w)+s^{u}(w) \quad \text { with } \quad s^{e}(w)=\lambda_{e} \int_{\underline{w}}^{\bar{w}} \varphi(x / w) f(x) d x .
$$

Besides we have $s^{e}(w)=\theta_{s}(w) s(w)$ and $s^{u}(w)=\left[1-\theta_{s}(w)\right] s(w)$. Analogously, define $R^{e}(w)$ as the number of recruits from employment, $R^{u}(w)$ as the number of recruits from non-employment and $\theta_{R}(w)$ as the share of recruits from employment. Thus, we get

$$
R(w)=R^{e}(w)+R^{u}(w) \quad \text { with } \quad R^{e}(w)=\lambda_{e} \int_{\underline{w}}^{\bar{w}} \varphi(w / x) L(x \mid \cdot) f(x) d x
$$

and $R^{e}(w)=\theta_{R}(w) R(w)$ as well as $R^{u}(w)=\left[1-\theta_{R}(w)\right] R(w)$.

Next, we define the corresponding elasticities. Let $\varepsilon_{R w}^{e}(w)$ and $\varepsilon_{R w}^{u}(w)$ denote the wage elasticities of recruits hired from employment and unemployment, and let $\varepsilon_{s w}^{e}(w)$ and $\varepsilon_{s w}^{u}(w)$ denote the wage elasticities of the separation rates to employment and unemployment. The overall long-run wage elasticity of a firm's labor supply becomes

$$
\varepsilon_{L w}^{L}(w)=\theta_{R}(w) \varepsilon_{R w}^{e}(w)+\left[1-\theta_{R}(w)\right] \varepsilon_{R w}^{u}(w)-\theta_{s}(w) \varepsilon_{s w}^{e}(w)-\left[1-\theta_{s}(w)\right] \varepsilon_{s w}^{u}(w) .
$$

This implies that $\varepsilon_{L w}^{L}$ can be estimated by estimating these four elasticities separately.

In this case a relationship similar to (9) can be derived. Absolute values of a weighted average of the separation rate elasticity to employment and a weighted average of the recruitment elasticity from employment are the same, where the weights are the number of separations to employment for the former and the number of recruits from employment for the latter. ${ }^{6}$ Thus, we get

$$
\int_{\underline{w}}^{\bar{w}} \varepsilon_{s w}^{e}(x) s^{e}(x) L(x \mid \cdot) f(x) d x=-\int_{\underline{w}}^{\bar{w}} \varepsilon_{R w}^{e}(x) R^{e}(x) f(x) d x
$$

5 It might be more adequate to distinguish employment and non-employment instead of employment and unemployment. However, due to the nature of the data we are going to use we cannot identify transitions to or from non-employment (other than unemployment) so that we will, unlike Manning (2003), model transitions to and from unemployment instead.

6 A formal proof of this is given by Manning (2003, pp. 109/10). 
so that both elasticities will be the same in absolute values if both are constant. In this case 13 can be used to obtain an estimate for $\varepsilon_{R w}^{e}$ from the estimate of $\varepsilon_{s w}^{e}$. In case of non-constant elasticities, however, we would be confronted with the problem of obtaining the weights of the averages.

What is left is finding a procedure to estimate $\varepsilon_{R w}^{u}$. Consider that the share of recruits from employment $\theta_{R}$ is $\theta_{R}(w)=R^{e}(w) /\left[R^{e}(w)+R^{u}(w)\right]$. Solving for $R^{u}(w)$ yields

$$
R^{u}(w)=\frac{1-\theta_{R}(w)}{\theta_{R}(w)} R^{e}(w) .
$$

Taking logarithms and derivatives of both left-hand and right-hand sides and some rearrangement give

$$
\varepsilon_{R w}^{u}(w)=\varepsilon_{R w}^{e}(w)-\frac{\theta_{R}^{\prime}(w) w}{\theta_{R}(w)\left[1-\theta_{R}(w)\right]} .
$$

Therefore we may use this relationship to estimate $\varepsilon_{R w}^{u}$ indirectly through $\varepsilon_{R w}^{e}$ so that we do not have to estimate recruitment elasticities at all.

To sum up, the relationships in equations (12), (13) and (15) enable us to apply the following procedure for identifying the labor supply elasticity: In the first step, we have to estimate the separation rate elasticity to employment $\varepsilon_{s w}^{e}$, which also provides, in the second step, an estimate of the recruitment elasticity to employment $\varepsilon_{R w}^{e}$. Third, we have to estimate the separation rate elasticity to unemployment $\varepsilon_{s w}^{u}$. Fourth, this estimate can be used to obtain an estimate of the recruitment elasticity from unemployment $\varepsilon_{R w}^{u}$. Finally, these four estimates can be combined to obtain an estimate for the long-run elasticity of labor supply to the firm.

\section{Empirical Specification}

The results presented in section 2 can now be used to estimate the long-run labor supply elasticity. Suppose there are $m$ workers with $N$ employment spells, indexed by $i=1, \ldots, N$, who work for $n$ firms, indexed by $j=1, \ldots, n$. Let $x_{i} \equiv\left(x_{i 1}, \ldots, x_{i k}\right)$ denote a vector of $k$ covariates observed for employment spell $i$. Next let $\beta \equiv\left(\beta_{1}, \ldots, \beta_{k}\right)^{\prime} \in \mathbb{R}^{k}$ denote a vector of $k$ coefficients which are the same for all spells $i=1, \ldots, N$. Analogously, $z_{j(i)} \equiv\left(z_{j(i) 1}, \ldots, z_{j(i) l}\right)$ is a vector of $l$ covariates observed for firm $j(i)$ for which the worker with spell $i$ is working. Eventually $\gamma \equiv\left(\gamma_{1}, \ldots, \gamma_{l}\right)^{\prime} \in \mathbb{R}^{l}$ denotes the corresponding vector of $l$ coefficients. 
Now we model the instantaneous separation rate to employment of the $i$-th spell at time $t$ conditional on $x_{i}$ and $z_{j(i)}$ as

$$
\sigma_{i}^{e}\left(t \mid x_{i}, z_{j(i)}\right)=\sigma_{0}^{e}(t) \exp \left(x_{i} \beta^{e}+z_{j(i)} \gamma^{e}\right)
$$

This gives a conditional hazard function with baseline hazard $\sigma_{0}^{e}(t)$, i.e. a Cox proportional hazard model. 7 Next, we model the instantaneous separation rate to unemployment in the same manner as

$$
\sigma_{i}^{u}\left(t \mid x_{i}, z_{j(i)}\right)=\sigma_{0}^{u}(t) \exp \left(x_{i} \beta^{u}+z_{j(i)} \gamma^{u}\right)
$$

Contrary to (16) and (17), Manning (2003) models instantaneous separation rates as exponential functions and fits an exponential hazard model. Assuming that these instantaneous separation rates are independent, Manning (2003, p. 101) shows that they can be estimated stepwise: Two estimations are done, each of them considering two states so that one has not to deal with competing risk models. The separation rate to unemployment is estimated using the whole sample, where transitions to unemployment and stayers are distinguished. The separation rate to employment is estimated using the sample of those employment spells not ending with a transition from employment to unemployment. In this case transitions to other firms and stayers are distinguished.

Although such a two-step procedure is also employed here, our approach of modeling the separation rates according to $(16)$ and $(17)$ is less restrictive. An exponential model such as Manning's assumes that there is no duration dependence, i.e. the conditional hazard function is constant over time. By contrast, our model allows for duration dependence, both positive and negative, as the baseline hazard is allowed to vary over time. The coefficient vectors in (16) and (17) can now be estimated using Cox' $(1972,1975)$ partial likelihood estimator without specifying the baseline hazard and, thus, without specifying duration dependence.

If $x_{i}$ includes spell $i$ 's $\log$ wage $\ln w_{i}$, the wage elasticities of the instantaneous separation rates are constant for all $x_{i}$ and $z_{j(i)}$ and are obtained from (16) and (17) by taking logarithms as

$$
\frac{\partial \ln \sigma_{i}^{\nu}}{\partial \ln w_{i}}=\frac{\partial \sigma_{i}^{\nu}}{\partial w_{i}} \frac{w_{i}}{\sigma_{i}^{\nu}}=\beta_{w}^{\nu} \quad(\nu \in\{e, u\}),
$$

where $\beta_{w}^{\nu}$ is the corresponding coefficient of log wage. Making use of $(18)$ the estimate

$\overline{7} \quad$ For details about hazard rate models and particularly the Cox proportional hazard model see Klein \& Moeschberger (2003). 
$\hat{\beta}_{w}^{e}$ gives an approximate estimate for the separation rate elasticity to employment $\hat{\varepsilon}_{s w}^{e}$, while the estimate of $\beta_{w}^{u}$ gives an approximate estimate for the separation rate elasticity to unemployment $\hat{\varepsilon}_{s w}^{u}$. Since the Cox proportional hazard models estimate constant separation rate elasticities, (13) says that absolute values of the separation rate elasticity to employment and the recruitment elasticity from employment are the same so that the estimate $\hat{\varepsilon}_{s w}^{e}$ provides also an estimate of $\varepsilon_{R w}^{e}$. Thus, we do not have to estimate $\varepsilon_{R w}^{e}$ on its own.

Finally, we model the share of recruits hired from employment $\theta_{R}$ as a standard logistic function, where now $i=1, \ldots, \tilde{N}$ transitions of $\tilde{m}$ recruits are considered. Hence, the probability that a recruit comes from employment $\operatorname{Pr}\left(y_{i}=1\right)$ becomes

$$
\operatorname{Pr}\left(y_{i}=1\right)=\theta_{R, i}\left(x_{i}, z_{j(i)}\right) \equiv \frac{\exp \left(x_{i} \beta+z_{j(i)} \gamma\right)}{1+\exp \left(x_{i} \beta+z_{j(i)} \gamma\right)}
$$

where notation follows the same rules as before and $y_{i}$ is a binary response taking on the value one if a recruit comes from employment and zero otherwise. If $x_{i}$ includes the worker's log wage $\ln w_{i}$ and $\beta_{w}$ denotes the corresponding coefficient, $\beta_{w}$ will be given by

$$
\beta_{w}=\frac{\partial \theta_{R, i}(\cdot) / \partial w_{i}}{\theta_{R, i}(\cdot)\left[1-\theta_{R, i}(\cdot)\right]} w_{i} .
$$

Since the estimated $\hat{\beta}_{w}$ is the same for all spells $i=1, \ldots, \tilde{m}$ we may drop the index $i$ and $(20)$ becomes exactly the second term on the right-hand side of (15). Therefore we can obtain $\hat{\varepsilon}_{R w}^{u}$ from $\hat{\varepsilon}_{R w}^{e}$ by subtracting $\hat{\beta}_{w}$ from the latter. To get an estimate for $\beta_{w}$ we fit a logit model for the probability that a recruit is hired from employment since a logit model uses a standard logistic link function.

In steady state the share of recruits from employment and the share of separations to employment must be the same so that we define $\theta \equiv \theta_{R}=\theta_{s}$. To obtain an estimate of $\varepsilon_{L w}^{L}$ making use of 12 we need to calculate $\theta$. Then we are able to estimate the long-run elasticity of firm's labor supply as

$$
\begin{aligned}
\hat{\varepsilon}_{L w}^{L} & =\theta \hat{\varepsilon}_{R w}^{e}+(1-\theta) \hat{\varepsilon}_{R w}^{u}-\theta \hat{\varepsilon}_{s w}^{e}-(1-\theta) \hat{\varepsilon}_{s w}^{u} \\
& =-(1+\theta) \hat{\beta}_{w}^{e}-(1-\theta)\left(\hat{\beta}_{w}^{u}+\hat{\beta}_{w}\right) .
\end{aligned}
$$

Manning (2003, pp. 100-5) uses this procedure to estimate labor supply elasticities for two American and two British datasets: the Panel Study of Income Dynamics and the National Longitudinal Study of the Youth from the U.S. as well as the Labour Force Survey and the British Household Panel Study from the UK. He fits exponential hazard models and does not estimate elasticities separately for men and women. Furthermore he uses datasets based on supply-side individual- or 
household-level surveys so that he is not able to control adequately for firm-specific determinants of transition behavior. For all four datasets estimated separation rate elasticities are negative, low in absolute value and statistically significant at the $1 \%$ level. The resulting long-run labor supply elasticities are quite low, ranging from 0.59 to 1.38 .

Ransom \& Oaxaca (2005) do analyze elasticities for men and women, but they use the restrictive specification with deterministic transition behavior across firms and totally wage-inelastic transitions from and to non-employment so that (6) applies. Using data from a chain of regional grocery stores from the U.S. they fit a probit model for the probability that a separation takes place. Again no firm-specific controls are added. Estimated supply elasticities, evaluated at the sample mean of the explanatory variables, are around 3.5 for male and around 2.7 for female workers (depending on specification), implying that firms have significant monopsony power. Moreover the noticeable difference in elasticities could give employers the opportunity of engaging Robinsonian wage discrimination which would mean that the more wage-elastic group, i.e. male workers, earns more ceteris paribus. Furthermore, using a Norwegian linked employer-employee dataset, Barth \& Dale-Olsen (1999) present some evidence that female turnover is less wage-elastic, but they do not report elasticities.

\section{Data}

The dataset used in subsequent empirical analyses is the German LIAB, i.e. the Linked Employer-Employee Dataset of the Institute for Employment Research (Institut für Arbeitsmarkt- und Berufsforschung, IAB) of the German Federal Employment Agency (Bundesagentur für Arbeit). More precisely, we will use version 2 of the LIAB longitudinal model and restrict our analyses to the year 2000 and western Germany. $]^{8}$ The LIAB is created by linking the process-produced person-specific data of the IAB with the IAB Establishment Panel (cf. Alda et al. 2005). Using the LIAB we are therefore able to control both for personal and establishment characteristics.

The employee history used for constructing the LIAB is based on the integrated notification procedure for the health, pension and unemployment insurances 9 This

8 There are two reasons for this restriction. Firstly, the structural approach we make use of assumes steady-state conditions. These are more likely to be found in western Germany than in eastern Germany that still experiences the long transition from a socialist to a capitalist economy. Secondly, unobserved heterogeneity is likely to cause a downward bias of the estimated separation rate elasticities (cf. Lancaster 1990, p. 304). Manning (2003, pp. 103/4) demonstrates that the bias is likely to be reduced markedly as the time period in consideration becomes shorter and concludes that the bias is likely to be small for a one year time horizon. Details are given by Alda et al. (2005) and Bender et al. (2000). 
procedure requires all employers to report all information of their employees if covered by the social security system, where misreporting is legally sanctioned. Notifications are compulsory at the beginning as well as at the end of employment. Additionally, an annual report must be made for each employee employed on December 31 of the year. As a consequence, only those workers, salaried employees and trainees who are covered by social security are included. Thus, among others, civil servants, self-employed, those in marginal employment, students enrolled in higher education and family workers are not included. All in all, approximately $80 \%$ of all people employed in western Germany are part of the employee history.

The data include, among others things, information for every employee on daily gross wage, censored at the social security contribution ceiling, on the employee's occupation and occupational status, on industry and on the start and end of each employee notification. Furthermore individual characteristics, such as age, schooling and training as well as nationality are contained ${ }^{10}$ Finally, an establishment number is included which is used to link the employee history and the IAB Establishment Panel.

The employer side of our dataset is given by the IAB Establishment Panel, a random sample of establishments (not companies) from the comprehensive Employment Statistics drawn according to the principle of optimal stratification.11. Strata are defined over plant sizes and industries, where all in all 16 industries and ten firm sizes are considered. Since the survey is based on the Employment Statistics aggregated via the establishment number as of June 30 of a year it only includes establishments which employ at least one employee covered by social security. Every year since 1993 (1996) the IAB Establishment Panel has surveyed the same establishments from all industries in western (eastern) Germany. Response rates of units which have been interviewed repeatedly exceed $80 \%$. The IAB Establishment Panel is created to serve the needs of the Federal Employment Agency so that the focus on employment-related topics is predominant. Questions deal, among other things, with the number of employees, the working week for full-time workers, overtime, the establishment's commitment to collective agreements, the existence of a works council, the establishment's performance and export share, the technological status of the industrial plant and the establishment size.

\footnotetext{
10 Due to notifications made in the case of changes which are relevant according to benefit entitlement rules there is also information on the person's marital status and the number of children. However, these variables contain much measurement error and are very fragmentary (cf. Alda 2005, p. 21) so that we will not make use of them.

11 Details about the IAB Establishment Panel are given by Kölling (2000).
} 
Linking both the IAB Establishment Panel and the employee history through the establishment number gives the LIAB ${ }^{12}$ In version 2 of the LIAB longitudinal model, used in the following analyses, employment and benefit notifications of people are provided for the years 1993 to 2003. Information on establishments is taken from the IAB Establishment Panel, where the number of panel establishments is limited to a selection to keep the dataset manageable. All in all, about 28.5 million notifications of 2.36 million employees and 5,300 establishments are included for western Germany. ${ }^{13}$

Version 2 of the LIAB longitudinal model enables us to use the available flow information of individuals to analyze the separation rates as discussed in section 3. viz. the separation rates to unemployment and employment, where employment refers to employment at another establishment. Due to inclusion of establishment data we are able to control as well for person-specific characteristics as for characteristics of the establishment the employee is working for or is entering. Therefore the labor market's demand- and supply-sides can be taken into consideration.

There are, however, some shortcomings due to the nature of the data. We are only able to consider transitions from employment to employment at another establishment and from employment to unemployment. Transitions from employment to non-employment outside unemployment cannot be analyzed. The reason is that the data do not indicate whether employees without further notifications have changed to non-employment without receiving benefits (that is without being registered as unemployed) or have become, for instance, civil servants or self-employed who are not included in the employee history.

Another shortcoming of the LIAB is that daily gross wages are censored at the social security contribution ceiling, viz. $€ 143.92$ in 2000 . Obviously, using wage data without any correction would give biased estimates. One way to deal with this problem is single imputation, i.e. imputing all censored wages with estimated wages. Assuming that daily gross wages have a log-normal distribution, which seems to be a plausible approximation, first a Tobit model is estimated, where the dependent variable is log daily gross wage and the independent variables are those included in further analyses. Then for every censored observation a random value is drawn from a normal distribution left-truncated at the social security contribution ceiling (with predicted log wage as mean, and standard deviation as estimated from the To-

\footnotetext{
12 Details about the different LIAB models and their versions are given by Alda (2005).

13 Since there is no detailed information on the number of hours worked, we exclude part-time employees and concentrate on full-time employees. Moreover, apprentices and a small number of employees experiencing recalls are excluded. Finally, notifications which start and end at the same day and benefit notifications which correspond to employment notifications at the same time are deleted.
} 
bit model). ${ }^{14}$ To avoid biased estimates this procedure is applied to log daily gross wages in all analyses to follow.

\section{Results}

Now we apply the structural estimation procedure developed in sections 2 and 3 to estimate the long-run wage elasticity of firm's female and male labor supplies. We fit Cox proportional hazard models for the instantaneous separation rates to employment and unemployment to obtain the corresponding separation rate elasticities (see, e.g., Klein \& Moeschberger 2003, ch. 8). We further estimate a logit model for the probability that a recruit is hired from employment, where the estimated coefficient for the log wage links the separation rate elasticity to employment and the recruitment elasticity from unemployment. All these estimates are done both without and with establishment controls.

Transition to employment. First of all we have to estimate the separation rate elasticity to employment. This is done by fitting a Cox proportional hazard model for the instantaneous separation rate to employment, using a sample of 256,238 employment spells at IAB Panel establishments, 17,486 of them ending with a transition to another establishment. Note that only those employment spells are considered which do not end in unemployment so that there are only spells ending with a transition to another establishment or spells being censored without such a transition.

First we include only person-specific controls (model 1a). The effect we are mainly interested in is the effect of the wage on the separation rate to employment, so $\log$ daily gross wage is included as an explanatory variable. Theory implies that this effect should be negative: The higher the wages paid, the lower should be the separation rate. To investigate the difference between men and women in wagerelated transition behavior we include both a dummy variable indicating whether the worker is male and an interaction term interacting the dummy variable with log daily gross wage. Since we argue that monopsonistic wage discrimination could be part of the explanation of the gender pay gap we expect women to be less wageelastic so that the interaction term should be negative.

There are several other variables which may influence the separation rate to employment so that controlling for these factors is necessary to get a reliable estimate for the separation rate elasticity of men and women. For instance, the transition behavior of German and non-German workers may differ. Next, the worker's age is

$\overline{14}$ For details on single imputation in the case of censored wages see Gartner (2005). 
related to his working experience and, thus, it is likely to reflect differences in general training and, consequently, in productivity due to job experience. Therefore poaching of experienced workers should be more frequent so that the instantaneous separation rate to employment should increase in age. Furthermore we expect investments in human capital to decline in age as the end of working life approaches. Hence, the impact of squared age should be negative. A similar story applies to worker's formal education. We distinguish six different groups: workers with neither apprenticeship nor Abitur (which is the German equivalent to A-levels or graduation from high school), those with only apprenticeship, those with only Abitur, those with both, workers with a technical college degree, and finally those with a university degree. Since we expect higher degrees of formal education to reflect higher productivity both in terms of signaling productivity and of higher investments in human capital, poaching should be more frequent for workers with higher formal education. Hence, their separation rate should be higher. By the same token, occupations which need more skilled workers should exhibit more poaching and should therefore have a higher separation rate to employment. We distinguish eleven groups of occupations: basic and qualified manual occupations, engineers/technicians, basic and qualified service occupations, semi-professionals and professionals, basic and qualified business occupations and, eventually, managers. 15

Estimation results for this model 1a are reported in table 1. As expected, women are less wage-elastic than men, their elasticity being estimated only as $-0.813 \mathrm{com}$ pared to -1.353 for men, where the difference represented by the interaction term is statistically significant at the $1 \%$ level. All in all, controls have the signs implied by theory. The estimated coefficient of age is significantly positive, the sign of the coefficient of squared age is significantly negative. Workers with higher formal education and in occupations requiring more skills tend to have higher separation rates. Separation rates do not differ significantly for non-German workers.

In a next step we include establishment controls which gives model 1b, estimates of which are reported in table 2. We now take into account that separation rates for workers of establishments belonging to different sectors may differ. Hence, we include ten sectoral dummies ${ }^{16}$ Since workers of different qualification as well as male and

15 One might also argue that tenure could influence the separation rate. However, one of the main theses of the new monopsony literature is that paying higher wages reduces separations and thus raises tenure so that excluding tenure may give better estimates (cf. Manning 2003, p. 103). Furthermore, version 2 of the LIAB longitudinal model up to now includes no reliable tenure variable so that we could not have controlled for tenure adequately even if we had wanted to.

16 Sectors are (1) agriculture, hunting and forestry (including fishing), (2) mining, quarrying, electricity, gas and water supply, (3) manufacturing, (4) trade and repair, (5) construction, (6) transport, storage and communication, (7) financial intermediation, (8) business activities, 
Table 1: Estimations without establishment controls ${ }^{a}$

\begin{tabular}{|c|c|c|c|}
\hline Dependent variables & $\begin{array}{c}\text { Model 1a } \\
\text { Transition to } \\
\text { employment }\end{array}$ & $\begin{array}{c}\text { Model 2a } \\
\text { Transition to } \\
\text { unemployment }{ }^{c}\end{array}$ & $\begin{array}{l}\text { Model 3a } \\
\text { Hiring from } \\
\text { employment }\end{array}$ \\
\hline Log daily gross wage (in $€$ ) & $-0.813^{* *}(0.189)$ & $-1.705^{* *}(0.094)$ & $1.645^{* *}(0.152)$ \\
\hline Male (dummy: $1=$ yes) & $2.823^{* *}(0.555)$ & $2.148^{* *}(0.559)$ & $(0.593)$ \\
\hline Male $\times \log$ daily gross wage (interaction term) & $-0.540^{* *}(0.128)$ & $-0.431^{* *}(0.135)$ & $-0.087 \quad(0.139)$ \\
\hline Age (in years) & $0.091^{* *}(0.013)$ & $-0.030 \quad(0.030)$ & $0.021 \quad(0.016)$ \\
\hline $\operatorname{Age}^{2} / 100$ & $-0.164^{* *}(0.020)$ & $0.034 \quad(0.040)$ & $-0.068^{* *}(0.023)$ \\
\hline Non-German (dummy: $1=$ yes) & $-0.140 \quad(0.072)$ & $0.168 \quad(0.097)$ & $-0.008 \quad(0.106)$ \\
\hline Without apprenticeship or Abitur (ref. group) & - & - & - \\
\hline Apprenticeship, no Abitur (dummy: $1=$ yes) & $-0.179^{*} \quad(0.073)$ & $-0.260^{* *}(0.088)$ & $0.170^{*} \quad(0.081)$ \\
\hline No apprenticeship, with Abitur (dummy: $1=$ yes) & $-0.108 \quad(0.196)$ & $-1.918^{* *}(0.568)$ & $1.219^{* *}(0.266)$ \\
\hline Apprenticeship and Abitur (dummy: $1=$ yes) & $0.112 \quad(0.078)$ & $-0.476^{* *}(0.120)$ & $0.410^{* *}(0.120)$ \\
\hline Technical college degree (dummy: $1=$ yes) & $0.355^{*} \quad(0.151)$ & $-0.106 \quad(0.117)$ & $0.446^{* *}(0.125)$ \\
\hline University degree (dummy: $1=$ yes) & $0.573^{* *}(0.155)$ & $-0.065 \quad(0.126)$ & $0.201 \quad(0.154)$ \\
\hline Basic manual occupation (ref. group) & - & - & - \\
\hline Qualified manual occupation (dummy: $1=$ yes) & $0.194 \quad(0.128)$ & $-0.344^{* *}(0.085)$ & $0.319^{* *}(0.101)$ \\
\hline Engineers and technicians (dummy: $1=$ yes) & $0.515^{* *}(0.105)$ & $-0.432^{* *}(0.142)$ & $0.569^{* *}(0.145)$ \\
\hline Basic service occupation (dummy: $1=$ yes) & $0.195 \quad(0.118)$ & $-0.329^{* *}(0.101)$ & $0.436^{* *}(0.123)$ \\
\hline Qualified service occupation (dummy: $1=$ yes) & $0.179 \quad(0.156)$ & $-0.432^{*} \quad(0.187)$ & $0.371 \quad(0.194)$ \\
\hline Semi-professional (dummy: $1=$ yes $)$ & $0.365^{* *}(0.118)$ & $-0.277 \quad(0.175)$ & $-0.024 \quad(0.144)$ \\
\hline Professional (dummy: $1=$ yes) & $0.715^{* *}(0.131)$ & $0.164 \quad(0.192)$ & $0.345^{*} \quad(0.165)$ \\
\hline Basic business occupation (dummy: $1=$ yes $)$ & $0.682^{* *}(0.118)$ & $-0.259^{*} \quad(0.120)$ & $0.428^{* *}(0.140)$ \\
\hline Qualified business occupation (dummy: $1=$ yes) & $0.637^{* *}(0.207)$ & $-0.521^{* *}(0.120)$ & $0.423^{* *}(0.107)$ \\
\hline Manager (dummy: $1=$ yes) & $0.944^{* *}(0.115)$ & $0.116 \quad(0.160)$ & $0.631^{* *}(0.157)$ \\
\hline Constant & - & - & $-6.839^{* *}(0.664)$ \\
\hline Observations & 256,238 & 266,792 & 30,481 \\
\hline Transitions & 17,486 & 10,554 & 30,481 \\
\hline Log likelihood & $-207,219$ & $-123,404$ & $-18,200$ \\
\hline McFadden- $R^{2}$ & 0.0201 & 0.0356 & 0.1030 \\
\hline
\end{tabular}

Notes:

${ }^{a}$ The dataset used is version 2 of the LIAB longitudinal model. Robust standard errors adjusted for intraestablishment correlations are given in parentheses. Asterisks indicate statistical significance: ${ }^{* *}$ at the $1 \%$ level and ${ }^{*}$ at the $5 \%$ level.

$b$ The dependent variable is a dummy variable taking the value one if the individual changes from an IAB Panel establishment to another establishment and zero otherwise. Only spells ending or beginning in 2000 which do not end with transition to unemployment are considered. A Cox proportional hazard model is fitted using partial likelihood.

${ }^{c}$ The dependent variable is a dummy variable taking the value one if the individual changes from an IAB Panel establishment into unemployment and zero otherwise. Only spells ending or beginning in 2000 are considered. A Cox proportional hazard model is fitted using partial likelihood.

${ }^{d}$ The dependent variable is a dummy variable taking the value one if the recruit of an IAB Panel establishment comes from employment and zero otherwise. Only transitions in 2000 are considered. A logit model is fitted using maximum likelihood. 
female workers differ in transition behavior it is likely that working for establishments with different proportions of qualified and female workers in the workforce makes a difference. Therefore we include the shares of qualified and female workers. Following the collective voice argument given by Freeman \& Medoff (1984), the representation of workers' interests either by a works council of by a union (via collective agreements at sectoral or firm level) may improve morale and thus reduce the separation rate to employment. Furthermore the existence of an occupational pension scheme might reduce the separation rate for those workers who would lose their contributions when quitting. Finally, we expect the separation rate to be lower in establishments with good economic performance and new production technology as these establishments may be more attractive employers. 17

As an (unreported) likelihood ratio test reveals, model $1 \mathrm{~b}$ fits the data significantly better. The establishment controls usually have the expected signs, although most of them are not significant. Only the proportion of female workers has a significantly positive impact on the separation rate, whereas the existence of a works council significantly reduces the separation rate. Industry affiliation and occupational variables also play a role. Adding establishment characteristics to the models reduces the estimated separation elasticities, whereas the size of the difference between female and male workers is nearly unchanged and remains statistically significant at the $1 \%$ level. With an elasticity of -0.569 , women are still less wage-elastic than men whose elasticity is estimated as -1.070 .

Transition to unemployment. After estimating the separation rate elasticity to employment we now turn to the separation rate elasticity to unemployment. Completely analogously, estimation is done by fitting a Cox proportional hazard model for the instantaneous separation rate to unemployment. The following estimates use a sample of 266,792 employment spells at IAB Panel establishments, where 10,554 transitions to unemployment take place. Spells ending with a transition from an IAB Panel establishment to another establishment are included as censored since no transition to unemployment takes place.

Again, we begin with including only person-specific controls (model 2a). Since we are now interested in the (instantaneous) separation rate to unemployment, the

(9) other activities and, finally, (10) non-profit organizations and public administration.

17 One might expect that establishment size, i.e. the total number of employees, is another influential variable. However, models of monopsony, such as the Burdett \& Mortensen (1998) model, imply that establishment size can (only) be extended by paying higher wages so that establishment size variables should be insignificant. In order to check this hypothesis we added establishment size and its square to models $1 \mathrm{~b}, 2 \mathrm{~b}$ and $3 \mathrm{~b}$. As expected, variables were insignificant in all estimations, as well on their own as jointly. 
Table 2: Estimations with establishment controls ${ }^{a}$

\begin{tabular}{|c|c|c|c|}
\hline Dependent variables & $\begin{array}{l}\text { Model 1b } \\
\text { Transition to } \\
\text { employment }^{b}\end{array}$ & $\begin{array}{c}\text { Model 2b } \\
\text { Transition to } \\
\text { unemployment }\end{array}$ & $\begin{array}{l}\text { Model } 3 \mathrm{~b} \\
\text { Hiring from } \\
\text { employment }^{d}\end{array}$ \\
\hline Log daily gross wage (in $€$ ) & $-0.569^{* *}(0.141)$ & $-1.646^{* *}(0.094)$ & $1.584^{* *}(0.135)$ \\
\hline Male (dummy: $1=$ yes) & $2.629^{* *}(0.495)$ & $1.658^{* *}(0.582)$ & $(0.566)$ \\
\hline Male $\times$ log wage (interaction term) & $-0.501^{* *}(0.112)$ & $-0.337^{*} \quad(0.137)$ & -0.180 \\
\hline Age (in years) & $0.081^{* *}(0.012)$ & -0.037 & $(0.016)$ \\
\hline $\mathrm{Age}^{2} / 100$ & $-0.150^{* *}(0.018)$ & $(0.037)$ & $-0.061^{* *}(0.022)$ \\
\hline Non-German (dummy: $1=$ yes) & $-0.158^{*} \quad(0.065)$ & $(0.096)$ & -0.055 \\
\hline Without apprenticeship or Abitur (ref. group) & - & - & - \\
\hline Apprenticeship, no Abitur (dummy: $1=$ yes) & $-0.167^{* *}(0.062)$ & $-0.242^{* *}(0.075)$ & $(0.074)$ \\
\hline No apprenticeship, with Abitur (dummy: $1=$ yes) & $0.145 \quad(0.132)$ & $-1.505^{* *}(0.471)$ & $1.117^{* *}(0.262)$ \\
\hline Apprenticeship and Abitur (dummy: $1=$ yes) & $0.068 \quad(0.112)$ & $-0.353^{* *}(0.113)$ & $0.311^{* *}(0.118)$ \\
\hline Technical college degree (dummy: $1=$ yes $)$ & $0.377^{* *}(0.128)$ & $-0.071 \quad(0.110)$ & $0.407^{* *}(0.120)$ \\
\hline University degree (dummy: $1=$ yes) & $0.525^{* *}(0.156)$ & $(0.110)$ & $(0.143)$ \\
\hline Basic manual occupation (ref. group) & - & - & - \\
\hline Qualified manual occupation (dummy: $1=$ yes) & $0.139 \quad(0.121)$ & $-0.315^{* *}(0.088)$ & $0.266^{* *}(0.101)$ \\
\hline Engineers and technicians (dummy: $1=$ yes) & $0.381^{* *}(0.107)$ & $-0.410^{* *}(0.147)$ & $0.539^{* *}(0.142)$ \\
\hline Basic service occupation (dummy: $1=$ yes) & $-0.011 \quad(0.114)$ & $-0.281^{* *}(0.086)$ & $0.421^{* *}(0.128)$ \\
\hline Qualified service occupation (dummy: $1=$ yes) & $-0.049 \quad(0.193)$ & $-0.263 \quad(0.188)$ & $0.488^{*}(0.192)$ \\
\hline Semi-professional (dummy: $1=$ yes) & $0.339^{*} \quad(0.147)$ & -0.164 & $(0.165)$ \\
\hline Professional (dummy: $1=$ yes) & $0.591^{* *}(0.134)$ & $(0.194)$ & $0.523^{* *}(0.182)$ \\
\hline Basic business occupation (dummy: $1=$ yes) & $0.438^{* *}(0.110)$ & -0.135 & $(0.143)$ \\
\hline Qualified business occupation (dummy: $1=$ yes) & $0.405^{* *}(0.090)$ & $-0.396^{* *}(0.108)$ & $0.331^{* *}(0.104)$ \\
\hline Manager (dummy: $1=$ yes) & $0.667^{* *}(0.127)$ & $(0.148)$ & $0.603^{* *}(0.160)$ \\
\hline Coll. agreement at sect. level (dummy: $1=$ yes) & $-0.064 \quad(0.081)$ & $(0.105)$ & -0.072 \\
\hline Coll. agreement at firm level (dummy: $1=$ yes) & $-0.052 \quad(0.224)$ & -0.248 & -0.008 \\
\hline Works council (dummy: $1=$ yes) & $-0.331^{* *}(0.093)$ & $-0.147 \quad(0.115)$ & $0.230^{*} \quad(0.101)$ \\
\hline Proportion of female workers & $0.478^{*} \quad(0.209)$ & $-0.469^{*} \quad(0.231)$ & $(0.225)$ \\
\hline Proportion of qualified workers & $-0.082 \quad(0.221)$ & -0.323 & $(0.187)$ \\
\hline Occupational pension scheme (dummy: $1=$ yes) & -0.221 & -0.077 & $(0.079)$ \\
\hline Good economic performance (dummy: $1=$ yes) & $-0.281 \quad(0.205)$ & $-0.321^{*} \quad(0.140)$ & $(0.097)$ \\
\hline New production technology (dummy: $1=$ yes) & $-0.039 \quad(0.131)$ & $-0.019 \quad(0.098)$ & $(0.094)$ \\
\hline Ten sectoral dummies ${ }^{e}$ & {$[0.0000]^{* *}$} & {$[0.0079]^{* *}$} & {$[0.0000]^{* *}$} \\
\hline Constant & - & - & $-8.747^{* *}(0.633)$ \\
\hline Observations & 256,238 & 266,792 & 30,481 \\
\hline Transitions & 17,486 & 10,554 & 30,481 \\
\hline Log likelihood & $-205,858$ & $-123,050$ & $-17,967$ \\
\hline McFadden- $R^{2}$ & 0.0265 & 0.0384 & 0.1145 \\
\hline
\end{tabular}

Notes:

${ }^{a}$ The dataset used is version 2 of the LIAB longitudinal model. Robust standard errors adjusted for intraestablishment correlations are given in parentheses. Asterisks indicate statistical significance: ${ }^{* *}$ at the $1 \%$ level and ${ }^{*}$ at the $5 \%$ level.

${ }^{b}$ The dependent variable is a dummy variable taking the value one if the individual changes from an IAB Panel establishment to another establishment and zero otherwise. Only spells ending or beginning in 2000 which do not end with transition to unemployment are considered. A Cox proportional hazard model is fitted using partial likelihood.

${ }^{c}$ The dependent variable is a dummy variable taking the value one if the individual changes from an IAB Panel establishment into unemployment and zero otherwise. Only spells ending or beginning in 2000 are considered. A Cox proportional hazard model is fitted using partial likelihood.

${ }^{d}$ The dependent variable is a dummy variable taking the value one if the recruit of an IAB Panel establishment comes from employment and zero otherwise. Only transitions in 2000 are considered. A logit model is fitted using maximum likelihood.

$e$ The joint statistical significance of the sectoral dummy variables is tested by performing a Wald test. The resulting $p$-value is reported in squared brackets. 
arguments considered for model $1 \mathrm{~b}$ suggest that age should have a negative impact, whereas its square should have a positive effect on the separation rate to unemployment. By the same token, the separation rate should be lower for those workers which have more formal education and those in occupations which require more skills. We expect establishments to lay off more skilled (i.e. more productive) employees less often than less skilled workers.

As can be seen from table 1, estimated coefficients tend to have the expected signs and they are for the most part significant. Only professionals and managers have the 'wrong' sign for the sample considered, although estimated coefficients are insignificant. Moreover, workers with technical college or university degrees do not have significantly lower separation rates to unemployment compared to apparently less skilled workers without apprenticeship or Abitur. The estimated separation rate elasticities of men and women differ significantly at the $1 \%$ level, with women's transitions to unemployment being less wage-elastic than men's with estimated elasticities of -1.705 and -2.136 , respectively.

Including the same establishment controls as in model 1b gives model 2b. Again, ten sectoral dummies are included because establishments belonging to different sectors may differ in layoff behavior. Since we found in model 2 a that separation rates differ by qualification and sex we include the proportions of female and qualified workers in the workforce because establishments with different shares of these groups may differ in layoff behavior as well. The existence of a works council or of collective agreements at sectoral or firm level may reduce the separation rate to unemployment as establishments may find it more difficult to lay off employees. Finally, establishments with a good economic performance should lay off workers less often so that the separation rate should be lower. In our eyes, the effect of new production technology and of an occupational pension scheme is unclear. Nonetheless, these control variables are included to guarantee estimates' comparability across models.

Performing a likelihood ratio test (not reported here), we find that model $2 \mathrm{~b}$ fits the data evidently better. Most establishment controls, however, are insignificant (even though most of them have the 'right' sign). The impact of person-specific controls is not changed. The sectoral dummies are jointly significant at the $1 \%$ level so that there are differences among sectors. As expected, firms with a good economic performance have significantly lower separation rates to unemployment. The estimated separation rate elasticity to unemployment is still significantly higher for men than for women. The difference in elasticities, however, is reduced with elasticities estimated as -1.646 for women and -1.983 for men. 
Hiring from employment. Finally, we have to fit a logit model for the probability that a recruit comes from employment, where the estimated coefficient of log wage links the separation rate elasticity to employment and the recruitment elasticity from unemployment. The following estimates use data of 30,481 recruits of IAB Panel establishments, where 18,797 of them are hired from employment and 11,684 from unemployment. First we include person-specific variables (model 3a).

We expect the probability that a recruit comes from employment and thus the share of recruits from employment to rise with the wage offered. That is to say that high-wage firms poach more effectively which is what theory predicts. One implication of this is that the recruitment elasticity from employment is higher than that from unemployment (cf. Manning 2003, p. 104). Furthermore, we expect that young and old workers are more often recruited from unemployment. The reason is that these groups are, for the same arguments given above, likely to have less human capital than middle-aged workers so that we expect less poaching for them. Put differently, competition among employers for these groups should be less intense. The same argument applies to workers' formal education and occupation. Workers with more formal education and workers in occupations requiring more skills should less often be hired from unemployment. By and large, the estimates of model 3a presented in table 1 confirm these expectations. The estimated coefficients of log daily gross wage for female and male recruits are 1.645 and 1.558, respectively. This difference, reflected by the estimated interaction term, however, is not statistically significant at conventional levels.

In model $3 \mathrm{~b}$ all the establishment controls from models $1 \mathrm{~b}$ and $2 \mathrm{~b}$ are included. Ten sectoral dummies control for differences among sectors since we expect establishments of different sectors to resort differently to unemployed workers. On account of asymmetric information on workers' productivity firms are likely to prefer recruiting from employment (through poaching). We therefore expect that establishments with a high share of qualified workers and new production technology recruit unemployed persons more infrequently. Since works councils and union collective agreements usually try to protect the insiders in a firm, their existence could be associated with a negative effect on the probability that a recruit is hired from unemployment. We also include the proportion of female workers in the workforce because the impact of gender is our main focus. Although the impact of good economic performance is unclear, we include this variable in order to guarantee comparability between the estimations done before and those here.

The results reported in table 2 show that there are noticeable differences among sectors and that the existence of a works council has a significantly positive impact 
on the hiring probability. The estimated coefficient of log daily wage reduces slightly compared to model 3a, while the difference between female and male workers is still statistically insignificant at conventional levels and small in size with estimated coefficients of 1.548 and 1.404 , respectively.

Obtaining Estimates for Labor Supply Elasticities. Combining these results we can now use equation (21) to obtain estimates for the long-run wage elasticity of firms' labor supply separately for female and male workers. Table 3 presents the results when using models $1 \mathrm{a}, 2 \mathrm{a}$ and $3 \mathrm{a}$, i.e. without establishment controls, or using alternatively models $1 \mathrm{~b}, 2 \mathrm{~b}$ and $3 \mathrm{~b}$, i.e. with establishment controls. The share of recruits from employment is obtained by calculating the sample average. In a steady state, assumed here, the share of recruits from employment must be equal to the share of separations to employment. As there are 17,486 separations to employment compared to 18,797 recruits hired from employment this seems to be a rather plausible assumption. Actually, the shares of separations to employment and recruits from employment for all workers deviate only slightly, viz. 0.623 compared to 0.617 . We shall use the share of recruits from employment in the following calculations.

Table 3: Estimates of the long-run wage elasticity of female and male labor supply to the firm ${ }^{a}$

\begin{tabular}{|l||c|c|c|c|}
\hline \multicolumn{1}{|l||}{ Groups: } & $\begin{array}{c}\text { Male } \\
\text { workers }\end{array}$ & $\begin{array}{c}\text { Female } \\
\text { workers }\end{array}$ & $\begin{array}{c}\text { Male } \\
\text { workers }\end{array}$ & $\begin{array}{c}\text { Female } \\
\text { workers }\end{array}$ \\
\hline \hline & $\begin{array}{r}\text { without establishment } \\
\text { controls }\end{array}$ & $\begin{array}{r}\text { with establishment } \\
\text { controls }\end{array}$ \\
$\begin{array}{l}\text { Estimated wage elasticity of the } \\
\text { separation rate to employment }\left(\hat{\beta}_{w}^{e}\right)\end{array}$ & -1.353 & -0.813 & -1.070 & -0.569 \\
$\begin{array}{l}\text { Estimated wage elasticity of the } \\
\text { separation rate to unemployment }\left(\hat{\beta}_{w}^{u}\right)\end{array}$ & -2.136 & -1.705 & -1.983 & -1.646 \\
$\begin{array}{l}\text { Estimated coefficient on log wage in a } \\
\text { logit model for the probability that a } \\
\text { recruit comes from employment }\left(\hat{\beta}_{w}\right)\end{array}$ & 1.558 & 1.645 & 1.404 & 1.584 \\
\begin{tabular}{l} 
Share of recruits from employment $(\theta)$ \\
\hline \hline $\begin{array}{l}\text { Estimated wage elasticity of firm's } \\
\text { labor supply }{ }^{b}\end{array}$
\end{tabular} & 0.624 & 0.599 & 0.624 & 0.599 \\
\hline
\end{tabular}

Notes:

${ }^{a}$ Estimated coefficients are taken from tables 1 and 2. Coefficients for men are gained by adding the corresponding interaction term to the coefficient of the reference group. Deviations are due to rounding differences.

${ }^{b}$ Estimated wage elasticities of firms' labor supply are obtained according to equation (21). 
Table 3 makes clear that labor supply elasticities are rather low and that there are substantial differences between male and female workers. While there is consensus that female labor supply is more elastic than male labor supply in terms of market supply (see, e.g., Cahuc \& Zylberberg 2004, p. 38), we find that female labor supply to the firm is less elastic than the labor supply of men. The estimated elasticity of women is, roughly speaking, only half the size of men's: 1.325 compared to 2.415 with person-specific controls and 0.935 compared to 1.956 when establishment controls are included, too. ${ }^{18}$

\section{Conclusions}

In this paper we have investigated women's and men's labor supply to the firm. We estimated labor supply elasticities within a structural approach resting on a dynamic model of new monopsony based on the Burdett \& Mortensen (1998) model. Unlike Burdett \& Mortensen (1998), we allowed for stochastic transitions between firms and wage-elastic transitions from and to unemployment, in such a way following Manning (2003). Estimations were carried out by methods of survival analysis, and we made use of the German linked employer-employee dataset LIAB for the year 2000. All in all, estimated elasticities were found to be small (between 0.9 and 2.4, depending on specification), and women's elasticity is only about half the size of men's. Although we have not been able to test for the structural approach chosen and although data restrictions did not allow us to investigate transitions to non-employment (rather than unemployment), our results should enable us to draw some cautious conclusions concerning the relevance and implications of gender differences in labor supply to the firm.

One important general insight is that estimated labor supply elasticities are far from the conventional textbook case of being totally elastic. This implies that the new monopsony approach is not rejected by the data, for its main feature is upwardsloping labor supply to the firm. Since the estimated elasticities are rather small in size, new monopsony models would suggest that firms have substantial monopsony power.

Confirming a presumption by Boal \& Ransom (1997), we found that (in contrast to labor supply at the level of the market) labor supply to the firm is less elastic for women than for men. Since this means that women's labor supply curve to the firm is

18 In order to investigate the results' robustness all the estimates were repeated for the year 2002 (results are available on request). Estimated supply elasticities for 2002 are even a little smaller than for the year 2000. Though there are minor changes in detail, women's labor supply remains substantially less elastic than men's. 
steeper than men's, our findings are consistent with those of Green et al. (1996) who report larger employer size-wage effects for women than for men. Furthermore, our results confirm and extend the two other attempts made to investigate women's and men's labor supply elasticities, namely the studies of Ransom \& Oaxaca (2005) and Barth \& Dale-Olsen (1999), since our analysis is built on less restrictive assumptions and explicitly controls for firm characteristics.

The substantial gender difference in labor supply elasticities found might give rise to wage discrimination in the spirit of Robinson (1933, p. 224), who argued that '[j] ust as we have price discrimination for a monopolist, so we may have price discrimination for a monopsonist.' This would result in lower wages for women, ceteris paribus, as a long-run equilibrium outcome since they are the less wage-elastic group. Whereas Robinsonian discrimination provides a relatively simple explanation for the persisting empirical regularity of the gender pay gap, it is difficult to interpret this pay gap as a long-run equilibrium outcome using Becker's (1971) concept of discrimination due to distaste without assuming some sort of market power on the demand-side. Moreover, employers' actions remain profit-maximizing when engaging in Robinsonian discrimination, whereas they must be biased by irrational prejudices when engaging in discrimination due to distaste because their profits are reduced in this case even if employers have considerable monopsony power (see, e.g., Bowlus \& Eckstein 2002).

An open question that could not be empirically investigated here is the reason for the less wage-elastic labor supply of women. Potential explanations are different preferences over non-wage job characteristics and a higher degree of immobility of women. Manning (2003, pp. 47-9, 199-208) presents some evidence for the U.S. and the UK that women are less driven by pecuniary considerations than men when changing jobs and face higher search frictions. For Germany, an analysis by Arntz (2005) shows that unemployed women are less inclined to leave local labor markets with an unfavorable labor demand situation than men, which points in the same direction.

Last but not least, we should also make clear that although female labor supply is less wage-elastic and labor supply elasticities are low so that Robinsonian wage discrimination might occur, '[i]t does not follow that differences in supply elasticities necessarily generate differences in wages. Before concluding that monopsony is important, one should measure outcomes.' (Hirsch \& Schumacher 2005, p. 987) Future research should try to take wage outcomes explicitly into account and investigate whether the gender pay gap is reduced if one controls for firms' monopsony power. If this were the case, the point of Robinsonian wage discrimination of women could be made even more convincingly. 


\section{References}

Alda, H. (2005), Datenbeschreibung der Version 2.0 des LIAB-Längsschnittmodells, Forschungsdatenzentrum des Instituts für Arbeitsmarkt- und Berufsforschung Datenreport Nr. 7/2005, Nuremberg.

Alda, H., Bender, S. \& Gartner, H. (2005), 'The linked employer-employee dataset created from the IAB establishment panel and the process-produced data of the IAB (LIAB)', Schmollers Jahrbuch (Journal of Applied Social Science Studies) 125(2), 327-36.

Arntz, M. (2005), The Geographical Mobility of Unemployed Workers: Evidence from West Germany, Centre for European Economic Research, ZEW Discussion Paper No. 05-34, Mannheim.

Barth, E. \& Dale-Olsen, H. (1999), Monopsonistic Discrimination and the Gender Wage Gap, National Bureau of Economic Research, NBER Working Paper No. 7197, Cambridge, MA.

Becker, G. S. (1971), The Economics of Discrimination, $2^{\text {nd }}$ edn, University of Chicago Press, Chicago, IL.

Bender, S., Haas, A. \& Klose, C. (2000), 'The IAB Employment Subsample 1975-95', Schmollers Jahrbuch (Journal of Applied Social Science Studies) 120(4), 64962 .

Bhaskar, V., Manning, A. \& To, T. (2002), 'Oligopsony and Monopsonistic Competition in Labor Markets', Journal of Economic Perspectives 16(2), 155-74.

Boal, W. M. \& Ransom, M. R. (1997), 'Monopsony in the Labor Market', Journal of Economic Literature 35(1), 86-112.

Bowlus, A. J. \& Eckstein, Z. (2002), 'Discrimination and Skill Differences in an Equilibrium Search Model', International Economic Review 43(4), 1309-45.

Burdett, K. \& Mortensen, D. T. (1998), 'Wage Differentials, Employer Size, and Unemployment', International Economic Review 39(2), 257-73.

Cahuc, P. \& Zylberberg, A. (2004), Labor Economics, MIT Press, Cambridge, MA.

Campbell, C. M. (1993), 'Do Firms Pay Efficiency Wages? Evidence with Data at the Firm Level', Journal of Labor Economics 11(3), 442-70.

Cox, D. R. (1972), 'Regression Models and Life-Tables', Journal of the Royal Statistical Society, Series B (Methodological) 34(2), 187-220.

Cox, D. R. (1975), 'Partial likelihood', Biometrika 62(2), 269-76.

Freeman, R. B. \& Medoff, J. L. (1984), What Do Unions Do?, Basic Books, New York. 
Gartner, H. (2005), The imputation of wages above the contribution limit with the German IAB employment sample, Forschungsdatenzentrum des Instituts für Arbeitsmarkt- und Berufsforschung Methodenreport Nr. 2/2005, Nuremberg.

Green, F., Machin, S. \& Manning, A. (1996), 'The Employer Size-Wage Effect: Can Dynamic Monopsony Provide an Explanation?', Oxford Economic Papers 48(3), 433-55.

Hirsch, B. T. \& Schumacher, E. J. (2005), 'Classic or new monopsony? Searching for evidence in nursing labor markets', Journal of Health Economics 24(5), 969-89.

Klein, J. P. \& Moeschberger, M. L. (2003), Survival Analysis: Techniques for Censored and Truncated Data, $2^{\text {nd }}$ edn, Springer, New York.

Kölling, A. (2000), 'The IAB-Establishment Panel', Schmollers Jahrbuch (Journal of Applied Social Science Studies) 120(2), 291-300.

Lancaster, T. (1990), The Econometric Analysis of Transition Data, Cambridge University Press, Cambridge.

Manning, A. (2003), Monopsony in Motion: Imperfect Competition in Labor Markets, Princeton University Press, Princeton, NJ.

Pigou, A. C. (1932), The Economics of Welfare, $4^{\text {th }}$ edn, Macmillan, London.

Ransom, M. R. \& Oaxaca, R. L. (2005), Sex Differences in Pay in a "New Monopsony" Model of the Labor Market, Institute for the Study of Labor, IZA Discussion Paper No. 1870, Bonn.

Robinson, J. (1933), The Economics of Imperfect Competition, Macmillan, London. 